\title{
Narrativas sobre a vida e o início do tratamento de uma paciente com Síndrome de Treacher Collins: um estudo de caso
}

\author{
Stories about life and treatment onset of a patient \\ with Treacher Collins syndrome: case study
}

\section{Elida Garbo Guedes ${ }^{1}$ (1) \\ Mariani da Costa Ribas ${ }^{2}$ (1) \\ Dagma Venturini Marques Abramides ${ }^{3}$ (1)}

${ }^{1}$ Autora para correspondência. Universidade de São Paulo (Bauru). São Paulo, Brasil. elida_garbo@yahoo.com.br 2,3Universidade de São Paulo (Bauru). São Paulo, Brasil. marianicribas@usp.br,dagmavma@usp.br

\begin{abstract}
RESUMO | Síndrome de Treacher Collins (STC) é uma anomalia do desenvolvimento craniofacial rara de manifestação clínica variável. Este estudo teve por objetivo principal analisar a experiência de uma mulher de 26 anos com STC que iniciou a reabilitação na idade adulta, buscando aprofundar possíveis impactos para o seu desenvolvimento. Com aprovação do Comitê de Ética em Pesquisa (CAAE 00981418.3.0000.5441), realizou-se um estudo de caso clínico por meio da análise documental do prontuário multiprofissional e uma entrevista semiestruturada gravada em áudio, transcrita integralmente e analisada qualitativamente pela técnica de Análise de Conteúdo de Bardin. Evidenciaram-se duas categorias temáticas que sinalizam a experiência de vida da participante dividida em dois momentos: (1)"Desenvolvimento até a fase adulta" que abarcou as subcategorias: "O que eu tenho?"; "Relacionamento com a mãe"; "Eu sofri bullying: desafio da escolarização" (2) "Ser alguém com Síndrome de Treacher Collins", e subcategorias: "Existem outros como eu: conhecendo o diagnóstico"; "Início do tratamento: desafios e expectativas"; "A psicologia e a equipe interdisciplinar"; "Mas hoje eu sou feliz: planos para o futuro". STC, sendo uma malformação facial, pode implicar em conviver com o estigma de não apresentar o rosto dentro dos padrões sociais impostos. No caso analisado, apontou-se sofrimento emocional, sendo este intensificado pelo não pedido de ajuda. Por outro lado, o diagnóstico da síndrome possibilitou o processo de identificação com outros sujeitos acometidos, o início da reabilitação e a vivência de impactos positivos em sua qualidade de vida. A psicologia figurou como espaço de escuta e possibilidade de reflexão sobre o processo de reabilitação.
\end{abstract}

PALAVRAS-CHAVE: Síndrome de Treacher Collins. Reabilitação. Família. Equipe interdisciplinar.
ABSTRACT | The Treacher Collins syndrome (TCS) is a rare anomaly of craniofacial development with variable clinical manifestation. The main goal of this study was to analyze the experience of a 26-year-old woman with TCS who initiated her rehabilitation in adulthood, aiming to deepen the possible impacts on her development. After approval by the Institutional Ethics Review Board (CAAE 00981418.3.0000.5441), the case study was conducted by documental analysis of the multiprofessional patient records and a semi-structured interview recorded in audio, transcribed in full and qualitatively analyzed by the Content Analysis technique of Bardin. Two theme categories were evidenced that indicated the life experience of the participant divided in two periods: (1) "Development up to adulthood", which included the subcategories: "What's wrong with me?"; "Relationship with the mother"; "I suffered bullying: challenge of school education" (2) "Being someone with Treacher Collins syndrome", and subcategories: "There are others like me: knowing the diagnosis"; "Treatment onset: challenges and expectations"; "Psychology and the interdisciplinary team"; "But I am happy today: plans for the future". Since TCS is a facial malformation, it may involve living with the stigma of not presenting a face within the imposed social standards. The present case presented emotional suffering, worsened because she did not ask for help. Conversely, the diagnosis of the syndrome allowed the process of identification with other affected individuals, the onset of rehabilitation and experience of positive impacts on her quality of life. Psychology participated as a space for hearing and possibility of reflecting about the rehabilitation process.

KEYWORDS: Treacher Collins syndrome. Rehabilitation. Family. Interdisciplinary team. 


\section{Introdução}

O desenvolvimento craniofacial é complexo e se torna suscetível a uma série de anomalias. Aproximadamente um terço das anomalias congênitas comprometem a cabeça e a face, sendo descritas até o momento mais de 700 variações delas. As disostoses faciais são um conjunto de anomalias raras do esqueleto craniofacial, heterogêneas quanto à etiologia e manifestação clínica, surgem como uma sequência anormal do desenvolvimento nos primeiros e segundos arcos faríngeos e seus derivados, acometendo maxila, mandíbula e as estruturas de suporte hióide. Podem ser subdivididas em disostose mandibulofacial e disostose acrofacial (Terrazas, Dixon, Trainor \& Dixon, 2017). A disostose mandibulofacial mais comumente descrita é a Síndrome de Treacher Collins (STC).

Andrade et al. (2005), ao resgatarem o histórico de identificação da STC, pontuam que esse é o nome usualmente escolhido para se referir a este diagnóstico, já que foi Treacher Collins em 1900 que descreveu seus componentes essenciais. Os autores apontam que a incidência da síndrome varia entre 1:40.000 a 1:70.000 nascidos vivos, sem dominância de sexo ou raça, de transmissão autossômica dominante e expressividade variável com grande diversidade de manifestação clínica.

A variabilidade de expressão clínica da síndrome dificulta a criação de guias de intervenção, porém as etapas da reabilitação visam preservar a pessoa acometida desde o início da infância, perpassando avaliações multiprofissionais (oftalmologia, otorrinolaringologia, fonoaudiologia, cirurgia plástica) e intervenções cirúrgicas, transcorrendo a reabilitação até a idade adulta (Alfonso \& Centeles, 2016). Os autores ainda pontuam a importância do suporte psicológico tanto para a família quanto para o sujeito em tratamento, devido às malformações e as diversas etapas cirúrgicas necessárias.

A STC pode ter como características a micrognatia (mandíbula pequena), hipoplasia malar, fendas palpebrais oblíquas anti-mongolóides, coloboma na pálpebra inferior (frequentemente acompanhado de ausência de cílios), fenda palatina, hipoplasia ou displasia do pavilhão auditivo e atresia do ouvido médio, que pode levar à deficiência auditiva condutiva (Pollo Medina, Álvarez, Torres, Placeres, \& Morales, 2014). A grande variação da expressão fenotípica da STC pode dificultar o diagnóstico, sendo importante o diagnóstico diferencial de outras síndromes como Nager e Miller, que possuem alguns comprometimentos similares. Assim também, o aconselhamento genético é complexo e necessário, pois a síndrome apresenta herança autossômica dominante, sendo que cerca de $40 \%$ dos casos tem histórico familial e $60 \%$ parecem ser devido a mutações novas (PassosBueno \& Splendore, 2001).

Lodovichi et al (2018) investigaram a percepção de qualidade de vida de sujeitos com STC com deformidade de orelha e sem deformidade e não encontraram diferença entre os grupos estudados, sendo que todos os sujeitos apresentavam escores elevados de qualidade de vida. Os autores pontuaram possíveis aspectos que possam ter gerado esse resultado, como a adesão a um protocolo adequado e individualizado de tratamento em um centro especializado, a oportunidade de acompanhamento psicológico longitudinal para o desenvolvimento de ferramentas de enfrentamento frente a insultos e bullying por pares e conhecimento do protocolo de tratamento que pode minimizar ansiedades naqueles com deformidades de orelha, pois os tornam conscientes do momento adequado para realização dos procedimentos de reconstrução. Os autores ressaltam, assim, a importância do tratamento especializado e em equipe interdisciplinar para favorecer o desenvolvimento dos sujeitos com STC com maior qualidade de vida minimizando os impactos estéticos e funcionais decorrentes da síndrome.

De Martini (2011) conceitua reabilitação como um trabalho com aspectos educacionais, sociais e terapêuticos maleáveis a partir de necessidades e situações peculiares. Nesse processo, a pessoa que sofre determinado tipo de comprometimento busca por restabelecer ou criar novos recursos para retomar da melhor maneira possível as atividades de vida. Assim, o autor pontua que é necessário que os profissionais compreendam que uma discussão estritamente técnica, que desconsidere situação social, econômica, questões familiares e escolhas individuais, produzirá um resultado insuficiente, ressaltando o trabalho interdisciplinar como essencial para a construção de uma reabilitação adequada e efetiva.

A prática do psicólogo em qualquer instituição de saúde terá como objetivo tratar do sofrimento, situação essa desencadeada pelo processo de adoecimento e/ou internação hospitalar (Mutarelli, 2015). 
A autora acrescenta que no hospital, instituição essencialmente curativa, o psicólogo deverá ser construtor de promoção de saúde, visando com sua atuação minimizar ou evitar sofrimentos emocionais adicionais ao adoecimento em questão, assim como apresenta esse profissional como o portador do olhar estrangeiro, aquele que direciona o olhar da equipe para a singularidade do paciente, o enxergando como único e portador do conhecimento de si mesmo. O psicólogo irá tecer em conjunto com a equipe a integração entre história de vida, processo de adoecimento e tratamento do paciente em questão.

É importante sinalizar a escassez de literatura sobre a síndrome que descreva o papel da psicologia no processo de reabilitação ou os aspectos psicológicos envolvidos em ser sujeito com STC. Dado o caráter raro desta síndrome e as particularidades da manifestação clínica, encontram-se na literatura publicada apenas relatos de caso direcionados a aspectos bastante específicos da reabilitação, como as intervenções cirúrgicas, otorrinolaringológicas e fisioterapêuticas.

Sendo assim, esse trabalho teve como objetivos analisar a experiência de uma paciente com STC que iniciou a reabilitação na idade adulta, buscando aprofundar os possíveis impactos para o seu desenvolvimento, e descrever o papel da psicologia enquanto participante da equipe interdisciplinar na reabilitação.

\section{Método}

O estudo foi realizado após a aprovação do Comitê de Ética em Pesquisa do Hospital de Reabilitação de Anomalias Craniofaciais HRAC/USP sob o parecer $n^{\circ}$ 3.051.962 (CAAE 00981418.3.0000.5441). No período do estudo o HRAC/USP apresentava 125 pacientes com diagnóstico da STC matriculados na instituição, destes, somente uma paciente se enquadrava nos seguintes critérios de inclusão: 18 anos ou mais independente de gênero, diagnóstico clínico de STC, não apresentar comorbidade diagnóstica, início do tratamento somente após os 18 anos. A paciente em questão, uma mulher com 26 anos de idade, matriculada na instituição em 18/04/2018, sem ter realizado tratamento específico para STC, foi convidada a participar desse estudo quando passava por atendimento individual no setor de psicologia da instituição, sendo apresentado a ela o estudo, seus objetivos e métodos assim como o Termo de Consentimento Livre e Esclarecido.
A mesma foi orientada que participar desse estudo daria acesso à exposição de informações pessoais que configuraria risco, uma vez que traria à memória experiências e situações vivenciadas de potencial sofrimento psíquico, sendo assim a psicóloga pesquisadora estava à disposição para interromper o estudo, oferecer acolhimento e suporte psicológico visando minimizar os impactos causados sempre que necessário. A participante estava ciente de que poderia deixar de participar do estudo sem impacto algum em sua reabilitação na instituição.

Para alcançar os objetivos propostos foi realizado um estudo de caso clínico por meio de análise documental do prontuário multiprofissional a fim de caracterizar os aspectos clínicos (diagnóstico, etapas terapêuticas) e psicossociais (perfil socioeconômico). Buscando conhecer a experiência individual da participante foi agendado um horário extra no setor de psicologia. Nesse atendimento, em sala que propiciava espaço de sigilo, foi conduzida pela psicóloga pesquisadora uma entrevista semiestruturada, partindo de três questionamentos iniciais: como tem sido sua experiência em ter a STC nos aspectos pessoal, familiar e social; fale sobre o seu tratamento; como você percebe a participação da psicologia em seu tratamento. Essa entrevista foi gravada em áudio, com a permissão da participante e analisada pela Técnica de Análise de Conteúdo de Laurence Bardin.

Desta forma, seguindo seus pressupostos, a análise foi realizada em três etapas, inicialmente o material foi organizado através da transcrição integral do áudio gravado e uma primeira leitura flutuante em busca de indicadores. Em seguida o material foi explorado por meio de novas leituras a fim de codificar os dados em unidades de registro. Esse processo foi construído com foco nos conteúdos que respondiam aos objetivos propostos. Para finalizar, os dados elencados foram tratados e interpretados, construindo-se, assim, por meio de agrupamento por semelhança e diferenciação, as categorias temáticas e subcategorias pertinentes ao tema. Caregnato e Mutti (2006) nomeiam essas etapas como pré-análise, exploração do material e tratamento dos resultados e interpretação. A interpretação e a inferência, segundo Câmara (2013) é o momento em que o pesquisador torna significativos e válidos os resultados brutos. Para Bardin (2009), a inferência na análise de conteúdo é um instrumento de indução para se investigar as causas a partir dos efeitos, e a interpretação só fará sentido quando se comparar os dados 
obtidos com a fundamentação teórica. Processo esse realizado na discussão.

\section{Apresentação do caso}

A participante do estudo é do sexo feminino, tem 26 anos de idade, estado civil solteira. Relatou como único tratamento o uso de aparelho ortodôntico desde 2016. Em avaliação inicial na instituição passou em atendimento com a equipe craniofacial composta por profissionais das seguintes áreas: cirurgia craniofacial, neurocirurgia, fonoaudiologia, genética, psicologia, ortodontia e serviço social. Os atendimentos foram individuais e posteriormente a equipe se reuniu para discussão do caso e definição de conduta.

O setor de genética confirmou a hipótese diagnóstica de STC, identificando as seguintes características clínicas (ou fenotípicas): ausência de fissura labiopalatina, fendas palpebrais oblíquas para baixo, coloboma de pálpebra inferior bilateral, hipoplasia/agenesia de arco zigomático, hipoplasia mandibular, orelhas discretas e proeminentes com leves alterações, a principal queixa apresentada foi dispneia.

A avaliação social pontuou classificação socioeconômica média inferior, destacando as seguintes características: ensino médio concluído, trabalhando como estoquista, residindo com três irmãos e um sobrinho, referindo bom relacionamento familiar e motivação para o tratamento.

Após a avaliação inicial, foi indicada como conduta cirúrgica o procedimento Expansão Rápida de Maxila Assistida Cirurgicamente (ERMAC) com o objetivo de expandir os segmentos maxilares. O procedimento foi realizado em 11/07/2018. Atualmente encontra-se em programação para cirurgia ortognática de maxila, mandíbula e mento.

\section{Resultados}

Após análise de conteúdo da entrevista, foi identificado que a experiência de vida da participante pode ser didaticamente dividida em dois momentos. O primeiro evidencia a categoria temática "Desenvolvimento até a fase adulta", que abarcou as seguintes subcategorias: "O que eu tenho?"; "Relacionamento com a mãe"; "Eu sofri bullying: o desafio da escolarização". O segundo momento evidenciou a categoria temática "Ser alguém com Síndrome de Treacher Collins", que por sua vez abarcou as subcategorias: "Existem outros como eu: conhecendo o diagnóstico"; "Início do tratamento: desafios e expectativas"; "A psicologia e a equipe interdisciplinar"; "Mas hoje eu sou feliz: planos para o futuro". Serão descritos os conteúdos significativos de cada categoria e subcategoria e as falas da participante estarão em destaque exemplificando a experiência relatada. $O$ primeiro momento da vida da participante foi descrito na categoria temática a seguir:

\section{Desenvolvimento até a fase adulta}

Ficaram agrupados nessa categoria os aspectos marcantes da experiência de vida da participante até a idade adulta, enquanto pessoa que sempre apresentou malformação facial, porém não soube que suas características eram indicadores do diagnóstico da STC. Seguem as subcategorias temáticas:

\section{O que eu tenho?}

A experiência de vida da participante foi marcada por crescer se percebendo diferente, com marcas no rosto e não entender o que tinha. Vivenciou inúmeras situações nas quais ser diferente transformava-se em ofensas, desde experiências no ambiente familiar como em outras situações sociais já na infância. Ela se percebia diferente, porém plenamente capaz. Essas vivências marcaram seu desenvolvimento.

"eu ol hava no espelho e não sabia o que era, nossa o quê que eu tenho? Será que tem um nome? Será que isso existe em outras pessoas? Eu não sabia completamente de nada... então foi muito difícil pra eu descobrir. "

“...e criança as pessoas sempre faziam piadinha, falam assim: se eu não era um acidente de carro, sempre tive assim esses joguinhos e criança não entende né, pode assim brigar, xingar e ela ali, que ela te abraça. "

Em sua experiência de vida ficou evidenciada sua forma de enfrentar as situações de discriminação, buscava não reagir às situações marcantes, porém vivenciava intenso sofrimento psíquico, tendo na fé sua esperança em algo melhor. 
"... eu toda a vida deixei as pessoas, eu não retrucava, eu aceitava... eu nunca deixei me abater, ficar ali recuada, isolada, eu já tive noite de choros, na minha fase de adolescência...".

\section{Relacionamento com a mãe}

Ao longo do relato da participante ficou evidente os aspectos que envolveram seu relacionamento com sua mãe, o vínculo forte entre elas, e os impactos da forma como sua mãe lidou com sua malformação e seu não tratamento na idade adequada. Ela relata perceber que sua mãe desejava poder cuidar de sua saúde, porém condições socioeconômicas, familiares e até emocionais limitavam suas possibilidades.

Houve um momento específico no qual ela expôs para a mãe seu desejo de buscar tratamento e entendeu as dificuldades da mãe nessa situação. O forte vínculo entre ambas é o balizador do enfrentamento das dificuldades vivenciadas.

"eu lembro que ela falou: você tem vontade de mexer no seu caso? Eu falei: tenho, tenho muita vontade! Nesse momento eu não aguentei, encheu os olhos de lágrima, comecei a chorar, e ela também, ela sofreu mais do que eu com o problema, ai foi onde ela falou que no momento certo Deus ia encaminhar as coisas certinha, e aí eu não tive mais coragem, aí ela ficou praticamente uns dois dias, assim, bem pra baixo, é engolindo lágrimas, eu entendia ela, porque pra ela era muito difícil, minha mãe teve 17 filhos, trabalhou muito na vida, chegou uma certa idade dela, ela não tinha mais saúde. Então quem precisava de ser cuidada não era eu, era ela. E isso eu fiz, cuidei dela até o ultimo dia dela".

Entretanto ao refletir sobre sua história de vida a participante questiona não ter conversado com a mãe sobre um possível tratamento e se arrepende.

"o mais incrível é que eu não conseguia passar isso para a minha mãe, eu não sei porque. Hoje eu arrependi, porque eu não sentei com ela: eu sei que a senhora não quis mexer no meu tratamento e tudo, mas me dá forças pra mim mesma seguir em frente e tirar aquele bloqueio dentro dela."

Em outro momento fica novamente evidente o vínculo forte entre ambas, pois a participante não responsabiliza a mãe por seu não tratamento, a mesma compreende as circunstâncias que podem ter influenciado a atitude passiva da mãe frente ao nascimento de uma filha com malformação e indica o quanto se sentia amada pela mãe.

"...e agradecendo também por eu não cobrar ela, em nenhum momento eu julgo ela, acho que eu como filha via o sofrimento nos olhos dela e se fosse por ela já estava encaminhado há muitos anos, mas ela não tinha forças, então essa parte ai eu respeitei, e o coração de mãe diz tudo né, então ela viu que no momento certo as coisas iam acontecer."

A participante percebe que a forma como sua mãe a tratava, fortalecendo sua esperança e estimulando sua fé, foi sua sustentação para enfrentar as situações difíceis no dia-a-dia.

\section{Eu sofri bullying: 0 desafio da escolarização}

O processo de escolarização para a participante foi marcado por inúmeras situações de bullying, durante a adolescência essa vivência se intensificou, marcando a forma como ela agia dentro da sala de aula, como se vestia e cuidava dos cabelos. Essa experiência foi de grande sofrimento psíquico, vivenciou esse processo sem queixar-se na escola ou para a família, assim não recebia ajuda adequada, sua fé era sua maior fonte de apoio.

"Acho que a pior fase foi a adolescência na escola, sofri vários bullying, eu não tinha amizade... foi bem preconceituosos... eu passei esse bullying, esse processo de preconceito calada, as vezes eu chegava a noite, eu chorava, escorria lágrimas dos meus olhos e pedia a Deus forças pra continuar a estudar, a viver, a ser feliz, a me olhar, então foi um processo assim de muita luta, aí era muito apelido, nossa é horrível! Aí, isso pra mim, eu não sei como eu terminei meu ensino médio..."

É evidente que mesmo enfrentando a violência psicológica e por vezes até física, a participante tinha por objetivo concluir sua escolarização para posteriormente trabalhar. O receio de ser ofendida modelava seus comportamentos na escola e a mesma buscava recursos para motivar-se, como a leitura.

"...eu vou terminar e logo depois trabalhar, aquele desejo de terminar logo, de trabalhar, mas no momento certo, então foi uma coisa assim que não tem nem explicação, eu me fiz também: como que eu consegui? Mesmo assim eu consegui, acho que era força, determinação, quero aprender, eu queria muito. 
Sua experiência escolar foi marcada por buscar se proteger da violência a qual era foco, assim sempre que possível evitava se expor deixando de participar de momentos importantes na vida escolar e escondia da família os eventos escolares. Porém, refere o intenso sofrimento psíquico em não vivenciar essas etapas importantes da vida escolar.

"eu me lembro que aquelas fotos de formatura eu não tirei, ia ficar exposto na escola, e eu não fui, depois eu arrependi, foi bobeira, eu deveria ter tirado a foto, fosse criticada ou não... eu vi que os alunos iam soltar uma piada, ali no momento e na hora de receber o diploma, ali terminado o ensino médio eu não fui também, mas essa parte me machucou muito eu deveria ter ido...e eu não contava também para minha mãe, eu não falava, teve coisa que ela nem soube."

O segundo momento de vida da participante, após o conhecimento de seu diagnóstico abarcou a seguinte categoria temática:

\section{Ser alguém com Síndrome de Treacher Collins}

Descobrir que suas características faciais são indicadores do diagnóstico de uma síndrome foi um momento marcante e repercutiu em um processo de identificação com outras pessoas com STC, favorecendo sua compreensão sobre suas dificuldades e também vislumbrar um processo de tratamento. A partir da visão de mundo da participante, entender seu diagnóstico foi como "sua hora chegar, pois Deus não desampara ninguém", sendo assim, seguem as subcategorias temáticas analisadas:

\section{Existem outros como eu: conhecendo o diagnóstico}

A participante cresceu se percebendo diferente, com características faciais marcantes e dificuldades funcionais na respiração. Assim, entender que esses aspectos eram indicadores de uma síndrome foi um momento de sentimentos ambivalentes, como choque e identificação. Permitiu a ela conhecer outras pessoas que vivenciam dificuldades como as suas e até mesmo mais intensas, já que a STC tem manifestação clínica bastante variável. Significando um marco em sua experiência pessoal, pois foi possível entender que seu sofrimento era de alguma forma compartilhado por outros, com vivências muito semelhantes às suas, ou até mesmo mais intensas, favorecendo seu processo de maturação emocional e enfrentamento das dificuldades. "quando eu descobri parece que tudo se abriu, tudo ficou mais claro pra mim [...] é um choque natural, não só eu que tenho, tem vários, então eu fiquei assim: nossa, pessoas com problemas bem mais graves, passando por uma cirurgia pesada, convivência e tudo,

porque o meu é a síndrome, mas um pouco leve, as pessoas já achavam totalmente diferente nas escolas $e$ tudo, preconceito, meu Deus!"

\section{Início do tratamento: desafios e expectativas}

Conhecer a síndrome possibilitou conhecer também o tratamento possível para suas dificuldades, tornando a participante bastante motivada e consciente para esse processo de cuidado que é longo e permeado por desafios. Vivenciar a reabilitação em um centro de referência proporcionou o processo de identificação com outras pessoas com STC e o desenvolvimento de vínculo de confiança com a equipe que $a$ atende.

"E a importância de eu me tratar aqui é que eu conheci as crianças com o mesmo caso, pessoas adultas, cada um com sua dificuldade, diferente, com sua superação... aí veio tudo pra cá, pra mim foi uma maravilha, porque assim o acolhimento, a humanização que você tem é imensa, referência, então o carinho."

A participante já realizou a primeira etapa cirúrgica do tratamento, momento permeado por expectativas e desafios intensos como entender o que cada procedimento pode trazer de impacto, o processo de hospitalização e a recuperação no pós-operatório.

"dá aquele frio na barriga, é uma expectativa isso, a gente fica ansioso, querendo que acontece logo, se vai dar certo ou não, só quer isso, não pensa em mais nada, uma alegria enorme, a dor faz parte, mas depois que você passa pela dor, mesmo com a dor, estou ainda feliz, eu sentia aquela, a ativação do aparelho, foi feita a disjunção palatina, toda vez que ativava doía muito, mas aquela dor ali eu ainda ficava feliz, logo vai passar, foi tão rápido, eu nem conseguia imaginar a dor que eu passei, a felicidade é maior, cobre tudo"

O processo de recuperação da intervenção cirúrgica envolve cuidados pós-operatórios que alteram a rotina diária da pessoa, como alimentação líquida, repouso, assim como as modificações estéticas provocadas pelo processo de recuperação repercutem no sentimento de bem-estar do sujeito, pois causam impactos transitórios não desejados, como relatado pela participante. 
“...eu fiquei 15 dias internada, inchou! Ficou bem inchado as bochechas, como eu praticamente não tenho queixo ficou totalmente sem. E eu fiquei um bom tempo em casa, pra trabalhar eu fui de máscara, vergonha, porque os meus dentes tinham afastado tanto que dava pra passar um dedo... eu evitava de sair, porque o povo olha e não entende, e são muitas perguntas, então eu preferia ficar dentro de casa e evitar essas perguntas."

A participante refere que essa primeira intervenção veio ao encontro com suas expectativas e já causou impacto em sua autoestima, sentimento de bem-estar, mesmo com os impactos negativos do processo de recuperação, a mesma está motivada para as próximas etapas cirúrgicas, pois almeja maior conforto estético e funcional com a respiração.

"eu tenho também essa grande expectativa, apesar dela ser muito dolorosa, mas eu nem penso nessa parte, acho que já passei fase pior, é os detalhes, eu conheço pessoas que não tem coragem de enfrentar a ortognática, o dia que você fizer uma você vai fazer tudo, porque a disjunção não é diferente, dessa que eu

vou fazer, quebra o osso ali, emagrece... a gente fica com vergonha [durante a recuperação da cirurgia], não fica legal, mas depois ia fechar com chave de ouro, com

o tempo, e foi isso que aconteceu"

\section{A Psicologia e a equipe interdisciplinar}

Ao ser abordada sobre sua experiência com profissionais de psicologia ao longo de seu tratamento, a participante cita que já realizou, em sua cidade de origem, psicoterapia e destaca os benefícios desse processo de autocuidado.

“...eu comecei minha consulta com psicologia né, tem dois anos mais ou menos, ai eu comecei eu parei, comecei de volta e foi muito bom, isso é uma parte muitíssimo importante pro tratamento, porque as vezes

o que a gente tem coragem de falar pro psicólogo a gente não tem coragem de falar pra uma outra pessoa."

A participante refere que o espaço de atendimento psicológico durante os retornos ao centro de reabilitação é importante para seu tratamento. Acrescenta que se tivesse tido acesso a esse espaço de autoconhecimento anteriormente, poderia ter vivenciado suas experiências de maneira diferente.

“...quem faz uma consulta com o psicólogo acho que ele consegue desabafar tudo que ele tem e isso acho que é bom, é ótimo poder ajudar o paciente, isso eu tiro por mim mesma, eu não contei, eu não tinha essa conversa com a minha mãe, hoje eu tenho com vocês, e me arrependo que não tive, talvez se eu tivesse um acompanhamento com psicólogo antes eu conseguiria chegar nela e conversar, mas eu não fui preparada."

A mesma acrescenta que nos atendimentos de psicologia pôde compreender como seria o processo de pós-operatório nos aspectos emocionais:

"acho que é primordial [atendimento psicológico], tem que ter, pro paciente tomar consciência do que ele vai passar, vai enfrentar tudo aquilo, saber lidar, então eu não tinha consciência de que meus dentes ia afastar, e que eu ia ficar certo receio, mas ai isso foi abrindo minha mente, pra eu me preparar antes, e graças a Deus deu certo, eu preparei a minha mente ... tem um processo de tempo pra chegar naquilo que ele quer..."

A participante tem entendimento sobre a diferença dos papéis profissionais da equipe e do profissional de psicologia, assim como valoriza a atuação de todos os profissionais que a acompanham.

"... com os profissionais a gente tem outras perguntas $e$ tudo, e eles, na linguagem deles é totalmente diferente, da cirurgia o que vai acontecer e tal, então essa parte como vai ficar ou não, eles têm esse cuidado, eles não querem deixar amedrontado o paciente, eu entendo o lado deles [equipe cirúrgica] acho que não é fácil, mas a psicologia desperta essa clareza todinha no paciente, deixa ele bem seguro e aí eu tomei a consciência, depois vai ficar ótimo, então isso faz com que o paciente tem a coragem de tomar a decisão e enfrentar o tratamento."

\section{Mas hoje eu sou feliz: planos para o futuro}

A participante manifesta gratidão por sua experiência pessoal e demonstra que sua fé a fortaleceu frente às suas vivencias tão intensas. Tem planos de estudar, e poder vivenciar momentos que durante o processo de escolarização básica foram marcados por sofrimento emocional.

“...é uma expectativa muito grande, eu acredito me sentir mais segura, mais conforto, eu acho que eu vou chegar na sala de aula eu vou me sentir à vontade, posso esclarecer um trabalho lá na frente, falar, rir, isso vai ser muito bom, muda, acho que muda tudo, não só o físico,

mas a mente, se sente assim mais segura, vontade de falar, pedir, vai tudo dando forças acho que eu já senti um pouco de mudanças e acredito que vai muito mais. " 
A tomada de consciência sobre sua síndrome e sua história pessoal marcada por preconceitos possibilitaram à participante refletir sobre relacionamentos afetivos com pessoas com a mesma síndrome e sobre ter filhos.

“...eu tenho essa síndrome, eu vejo como normal, acho que não teria problema nenhum se me relacionasse

com outro TC, lógico! Agora a opção de eu ter um

filho TC acho que eu não, não é que eu não aceito, é a dificuldade que ele pode enfrentar futuramente, aquilo que eu passei eu não quero que o outro passe. Então assim, as pessoas podem pensar que é preconceito, mas não, é só quem carrega é que sabe os obstáculos que tem pra enfrentar. Uma pessoa que vai viver no hospital, vai passar por uma barreira muito grande, na sociedade, no trabalho, achar que você não tem capacidade, ele tem capacidade!"

A orientação da geneticista da equipe possibilitou que a participante pudesse ressignificar seu sonho de ser mãe por meio da adoção, por exemplo.

"a geneticista falou: é jogar uma moeda, cara ou coroa - eu falei assim: olha, hoje em dia têm tantos meios de querer ter um filho, e pode adotar uma criança que está sofrendo em um orfanato, eu acho que isso pra mim nunca foi uma dificuldade, acho que ajudar o próximo,

é bem melhor que você querer matar sua própria vontade que talvez vai te trazer uma dificuldade imensa, não que eu tenha preconceito, jamais! "

\section{Discussão}

O primeiro momento de vida da participante, no qual se destacou a categoria "Desenvolvimento até a fase adulta", abarcou suas experiências pessoais marcadas pelo desconhecimento da síndrome, preconceito, violência psicológica (bullying), assim como, indica como o enfrentamento da mãe, sua figura de referência, perpassou o seu próprio enfretamento de sua condição.

Alves (2016) discorre sobre como o conceito de beleza e estética se impõem ao existir, tendo a aparência física importante significado no bem-estar psicossocial das pessoas, associando-se a beleza (constructo social) à bondade. Assim, o rosto desfigurado foge dos padrões de beleza preconizados e a pessoa com deformidade facial passa a conviver com o estigma. Essa marca, que se destaca e afasta, impossibilita que outros atributos da pessoa acometida sejam notados. Entende-se como a noção de estigma ao conviver com uma malformação facial em uma sociedade com padrões de beleza inalcançáveis impactou em seu desenvolvimento.

A autora acrescenta o rosto como a expressão da identidade pessoal, o meio pelo qual se é reconhecido, sempre revelador de subjetividade, fundamental na comunicação verbal e não verbal, sendo que a atração física também perpassa pelo rosto "belo". Assim, compreender em profundidade o significado do rosto para o sujeito pressupõe estar ciente que o próprio dono não é capaz de vê-lo sem ajuda de espelho, ele é visto pelo olhar do outro e sua reação. A boca e o sorriso compõem esse rosto e possibilitam uma gama imensa de significados e representações, é por meio deles que se conhece e participa do mundo e as sensações e os sentimentos perpassam. Apresentar comprometimentos nesses elementos pode impactar na participação social desse sujeito, pois os valores associados à beleza ou ausência dela estarão intimamente ligados à aceitação desse sujeito nos ambientes que frequentará (Alves, 2016).

Sendo assim, entende-se os questionamentos vividos pela participante ao longo de todo seu desenvolvimento até ter conhecimento de sua síndrome, destacados na subcategoria "O que eu tenho?", pois vivenciou todo o estigma de apresentar um rosto diferente que se distancia do padrão de beleza cobrado socialmente, e também como os sujeitos com os quais interagia construíam sua visão sobre a participante, pressupondo possíveis incapacidades e produzindo chacotas ofensivas.

É presente na psicologia a preocupação com os efeitos do estresse, entendido como uma reação do organismo frente a uma ameaça a sua estabilidade, envolvendo componentes físicos, psicológicos, mentais e hormonais (Lipp \& Malagris, 2011 como citado em Seidl et al, 2018), na saúde física e mental da pessoa que o vivencia. Ao analisar a experiência descrita pela participante, é possível identificar a presença de um estressor (aquilo que gerou a reação de estresse) contínuo em seu desenvolvimento, o preconceito, e o impacto emocional desse processo, como choros e fragilidade emocional. Entretanto é percebido também, com frequência, o desejo e motivação para vencer essas situações fazendo com que a mesma não desistisse de frequentar a escola, por exemplo. 
Ainda de acordo com Seidl et al (2018) outro conceito importante nesse contexto é o enfrentamento, entendido como esforços cognitivos e comportamentais voltados para o manejo de exigências de demandas internas ou externas que são avaliadas como sobrecarga aos recursos pessoais. Assim, os esforços visam administrar (reduzir, minimizar ou tolerar) essas demandas da relação pessoa - ambiente, sendo essa relação dinâmica e recíproca. A participante vivenciou esses processos sem pedir ajuda.

Foi identificado ao longo da entrevista o papel que o relacionamento com a mãe significou no não tratamento na idade adequada e também no processo de enfrentamento das dificuldades vivenciadas pela participante, evidenciando então a subcategoria "Relacionamento com a mãe".

Pode-se identificar que a mãe da participante enfrentou condições socioeconômicas vulneráveis. Além disso, o nascimento de uma criança com comprometimentos e/ou deficiência pode provocar uma crise na família, ocasionando abalo em sua identidade, estrutura e funcionamento. Por vezes a família se percebe despreparada para enfrentar essa realidade que exigirá quebra de expectativas, novas demandas emocionais e a convivência com a criança com necessidades diferenciadas. A família busca se adaptar e se reorganizar frente à realidade, mas esse reajuste pode requerer tempo. Sendo assim, há famílias que gerenciam essa transformação e outras têm maior dificuldade, demonstrando desesperança e percebendo sua estrutura ameaçada, com capacidade reduzida de reação frente a essa situação de crise (Barbosa, Balieiro \& Pettengell, 2012).

A deficiência, desde o nascimento, como diz De Martini (2001) pode impactar em prejuízo para o desenvolvimento quando a situação é interpretada com medo e desconhecimento, resultando em ambientes de superproteção ou depreciação, impactando no desejo da criança de explorar seu corpo e mundo.

Os primeiros anos de vida da criança constituem um período crucial para o desenvolvimento de recursos que se farão presentes ao longo de toda a vida, o que mais tarde compreendemos como seus aspectos motores, fisiológicos, afetivos ou psíquicos, e que estão implicados diretamente nas relações que a pessoa tem com o espaço físico, com seu próprio corpo e o dos outros (sua imagem corporal), com seus interesses, habilidades e assim por diante (De Martini, 2011, p 2266).
O resultado desse processo de desenvolvimento, facilitador ou não, implicará na reabilitação. Para adultos dependentes e passivos, o processo de reabilitar implicará em permitir, pela primeira vez, desenvolver recursos para assumir com autonomia aquilo que tem necessidade de fazer, podendo significar uma profunda mudança nas representações que a pessoa tem de si própria e de suas relações (De Martini, 2011). Este processo foi identificado na participante de estudo.

Os vários aspectos que podem ter influenciado no enfrentamento da mãe da participante sobre a condição de malformação da filha impactaram no seu desconhecimento de que essa condição indicava o diagnóstico de uma síndrome, assim como o não tratamento na idade adequada. Porém, pode-se identificar também que a participante compreende esses possíveis aspectos e não responsabiliza a mãe diretamente, no entanto, vivencia momentos de sentimentos ambivalentes por não ter solicitado ajuda e nunca ter proposto uma conversa sobre a questão com sua genitora.

Regen (2006), ao ponderar sobre família e deficiência, indica que o papel da família estável é possibilitar um campo de treinamento seguro no qual as crianças podem aprender a ser mais humanas, a amar, constituir sua personalidade, desenvolver sua autoimagem e a se relacionar com a sociedade mais ampla e imutável na qual nasceram, indicando a grande importância da família como primeira célula social da qual se faz parte e principal responsável pela formação individual e social. Com suas características próprias, percebe-se que para a participante o forte relacionamento com a mãe possibilitou a aprendizagem de valores importantes como o respeito, educação para com o outro e a fé religiosa, sendo suas bases para o enfrentamento pessoal das dificuldades.

A última subcategoria elencada, quando se observa o desenvolvimento da participante anterior ao diagnóstico da síndrome, é a experiência do processo de escolarização marcado por intenso bullying. Durante toda a vida escolar, ser diferente foi eliciador de violência psicológica, inúmeras chacotas e ofensas, processos que produziram intenso sofrimento psíquico a ela. O bullying como fenômeno social é entendido por Moreira (2012) como atos de violência física ou psicológica intencionais e repetidos, praticados por um indivíduo ou grupo de indivíduos com o objetivo de intimidar ou agredir outro indivíduo, podendo ocorrer em ambiente escolar ou empresarial, produzindo efeitos nocivos na vítima. 
A presença desse fenômeno durante longos anos pode propiciar certa desestruturação psicológica, porém é necessário compreender que essa questão está presente na base da sociedade de maneira estrutural, socioeconômica, cultural e principalmente na moral humana. O manejo dessa situação, portanto, depende da tríade família, escola e sociedade, cada qual desempenhando seu papel educador (Moreira, 2012).

A participante descreve que o período mais difícil de sua vivência escolar foi durante a adolescência, momento no qual não teve amigos e a questão estética ganha impacto mais característico. Abreu e Zacharias (2016) referem que essa fase do desenvolvimento humano é permeada por questionamentos, mudanças, preocupações com o corpo e incertezas, sendo um período difícil, autoimagem e autoestima são impactados pelos padrões estéticos impostos pela sociedade e reforçados pela mídia, como já refletido anteriormente. Acrescentam que as mulheres são, de fato, o principal alvo dessa questão podendo sofrer impacto emocional quando não conseguem corresponder ao padrão imposto, permeado por sentimento de frustração, medo, angústia, insegurança, que podem levar a depressão.

Vivenciar a adolescência, como momento natural de questionamentos e mudanças físicas e psicológicas, atrelada à malformação facial, ao bullying intenso e com postura menos ativa, sem solicitar ajuda na escola ou para a família foi gerador de intenso sofrimento emocional para a participante. Fica evidenciado que sua fé produzia esperança de alguma mudança e a fortalecia para viver essa transição, concluir a escolarização básica e futuramente trabalhar, assim como recursos como literatura a auxiliava.

Ainda de acordo com Abreu e Zacharias (2016) a família é fundamental no manejo das problemáticas características da adolescência, principalmente quando nesse momento se soma o bullying no ambiente escolar, pois a família é o ambiente que molda, mostra o mundo, ensina a seguir. Os sujeitos presentes nessa dinâmica, assim como a escola, devem ser parceiros para compreender a gravidade do problema e estimularem a criação de espaço de conscientização (Abreu \& Zacharias, 2016).
Gómes-Ortiz, Del Rey, Bolamos e Ruiz (2014) procuraram estudar as possíveis relações entre estilos parentais e atores envolvidos no bullying (agressores, vítimas, vítimas-agressores) e encontraram algumas pesquisas que propuseram relações possíveis, especificamente na qualidade da comunicação entre pais e filhos e problemas de vitimização e violenta conduta escolar, indicando maior chance de envolvimento com esse fenômeno naqueles adolescentes que percebem a comunicação negativa com os pais. Os autores, porém, deixam claro que essas análises são incipientes e podem depender da realidade sociocultural e escolar na qual o fenômeno bullying está ocorrendo. Sendo assim, é possível indicar uma provável relação entre o papel de vítima passiva da participante desse estudo e sua comunicação pouco efetiva com sua mãe, na qual aquela por vezes desejava propor conversas importantes à sua genitora, mas estava constantemente preocupada com o bem-estar da mãe, que se apresentava fragilizada quando o assunto perpassava a malformação da fiIha, a participante então permanecia calada e sem receber a ajuda da qual necessitava.

O segundo momento identificado ao longo da análise evidenciou a categoria temática "Ser pessoa com STC", a qual pode ser dividido didaticamente em subcategorias: "Existem outros como eu: conhecendo o diagnóstico"; "Início do tratamento: desafios e expectativas"; "A psicologia e a equipe interdisciplinar" e "Mas eu sou feliz: planos para o futuro".

Conhecer o diagnóstico da STC para a participante foi um momento de ambivalência emocional, pois vivenciou o impacto inicial de choque, porém pôde compreender que não é única, conhecendo outros indivíduos com a mesma síndrome que apresentam graus de comprometimentos variados. Oliveira-Cardoso, Garcia, Santos e Santos (2018), ao discorrerem sobre o impacto de um diagnóstico, referem que nesse momento se apresenta com clareza para o sujeito a necessidade de reconfigurar sua rotina e revisar seus planos. Incertezas e inseguranças são suscitadas e um tratamento se anuncia, possibilitando a instalação de uma crise permeada por fragilidade emocional, sendo necessário o sujeito se sentir acolhido e amparado nesse período delicado de sua vida. A participante, ao conhecer seu diagnóstico, pôde conhecer outros com a mesma síndrome e se identificar com eles, percebendo-se pertencente a um grupo que experiencia dificuldades semelhantes, seja em nível funcional ou social. 
A subcategoria "Início do Tratamento" descreve essa experiência como um momento marcado por expectativas e desafios, a participante já realizou a primeira intervenção cirúrgica e descreveu os impactos vivenciados durante o período de internação como inchaço e dores. No momento pós-operatório já em casa precisou adaptar-se às mudanças estéticas e funcionais transitórias, como espaçamento entre os dentes e voz assoprada, até que pôde identificar os impactos positivos dessa intervenção, como se sentir melhor consigo mesma e autocuidado.

Carvalho, Martins e Barbosa (2012) apontam que sujeitos com deformidade dentofacial tendem a apresentar altos níveis de ansiedade, reduzida satisfação com a imagem facial e dentária, reduzida autoestima, sentimento de insegurança, como pontuado pela participante em diversos momentos da entrevista. Acrescentam, portanto, que se faz necessário uma boa preparação desse sujeito para manejar os impactos emocionais presentes ao longo de uma intervenção cirúrgica ortodôntica, por se tratar de intervenções invasivas na zona mais exposta do corpo (face).

No momento, a participante aguarda com grande expectativa a programação da próxima cirurgia, ortognática, porém, apresenta-se bastante consciente dos processos envolvidos nesse procedimento cirúrgico. A cirurgia ortognática permite melhora na oclusão dentária, estética facial, função mastigatória e função respiratória, sendo, principalmente, o impacto estético a grande motivação para aqueles em preparação, geralmente acompanhado por expectativas de benefícios psicológicos associados (Carvalho et al, 2012).

Mutarelli (2015) pontua que estar no ambiente hospitalar impacta em quebra de rotina do sujeito que está vivenciando o cuidado assistencial curativo, baseado no modelo médico. Assim, cabe ao psicólogo, nesse contexto, buscar oferecer condições para que a internação possa ser vivenciada de maneira saudável do ponto de vista psíquico e a experiência do adoecimento possa integrada à própria história do sujeito, atuação como promoção de saúde.

Explorando a percepção da participante sobre o papel da psicologia ao longo de seu tratamento evidenciou-se a subcategoria temática "A psicologia e a equipe interdisciplinar", na qual se identificou que a participante valoriza os atendimentos de toda a equipe que a acompanha pontuando o papeis pertinentes a cada área. $\mathrm{O}$ ambiente hospitalar no modelo curativo favorece que a relação estabelecida entre equipe de saúde e paciente/família seja extremamente impessoal, cada profissional com seu saber realiza seus procedimentos de cuidados sem necessariamente conhecer a singularidade do paciente. Cabe, então, ao psicólogo, nesse espaço e capacitado para o olhar individualizado, ocupar o lugar de trazer para os demais profissionais da equipe as idiossincrasias do paciente, o entendimento do funcionamento emocional do mesmo e ajudar equipe e paciente a buscar estratégias de enfrentamento para as possíveis questões que estão impactando no tratamento (Vieira e Waischunng, 2018).

A participante observa que os atendimentos com a equipe de psicologia da instituição foram fundamentais para a preparação para o procedimento cirúrgico realizado, oportunizando espaço no qual pôde refletir criticamente sobre os processos que envolveriam o momento cirúrgico, pós-operatório e adaptação às mudanças decorrentes do procedimento. Indo ao encontro, destaca-se o papel do psicólogo hospitalar, que é atuar em conjunto com a equipe de saúde visando promover apoio e segurança ao paciente e seus familiares, mediante colaboração na tomada de decisões em relação às condutas a serem tomadas (Borges \& Soares, 2018).

Os pacientes, por vezes, recebem informações dos médicos e cirurgiões que os deixam tranquilos ou que provocam questionamentos, assim esses pacientes precisam de espaço de escuta, liberdade para externalizar seus sentimentos frente a situação real que enfrentam. Cabe, portanto, ao psicólogo enquanto profissional atuante com a esquipe multiprofissional, de acordo com Saldanha, Rosa e Cruz (2013), ajudar paciente e família a lidar com os conteúdos emocionais que emergem por meio de fantasias, medos e duvidas após essas conversas e orientações com equipes de saúde.

Como última subcategoria, "Mas hoje eu sou feliz; planos para o futuro", ficou evidenciada a motivação da participante com relação a seu futuro, indicando planos de estudar curso superior, e principalmente o impacto com a tomada de consciência de ter uma síndrome e sua decisão sobre ter filhos. A mesma, ao compreender o risco genético de ter um filho com o mesmo diagnóstico, ressignificou seu sonho materno por meio da possibilidade de adoção. O aconselhamento genético (AG) tem diversos objetivos, desde a definição de um diagnóstico, até a compreensão do 
prognóstico e risco de ocorrência e/ou recorrência da questão genética investigada. Assim, uma finalidade crucial do AG é possibilitar a tomada de decisão consciente e equilibrada sobre a saúde própria e de familiares (Hannum, Miranda, Brito, Costa-Neto e Cruz, 2015).

A área da saúde tem adotado o termo resiliência para se referir aqueles que apresentam adaptação positiva diante de uma ameaça. A partir da história de vida da participante, marcada por dúvidas, receios, preconceito, sofrimento emocional e intenso desejo de seguir em frente e fé em aguardar o "bom que está por vir", pode-se sugerir que ela é uma pessoa resiliente, entendendo que ser resiliente não significa ausência ou imunidade a riscos, mas um processo dinâmico de adaptação frente a vivência de experiências adversas (Seild et al, 2018).

\section{Considerações finais}

O presente estudo analisou a experiência de uma pessoa com STC e pôde apresentar as especificidades de sua história de vida perpassada pelo desconhecimento de seu diagnóstico, consequente início tardio de sua reabilitação, deixando evidente os impactos para seu desenvolvimento como intenso sofrimento emocional no período da escolarização básica, postura menos ativa no enfrentamento dessa questão e a comunicação deficitária com sua mãe, mesmo que o vínculo afetivo entre ambas tenha se apresentado positivo. Pode-se identificar também a importância do início do tratamento como uma oportunidade de ressignificar sua experiência de vida.

Porém, é necessário pontuar a limitação desse estudo ao analisar um único caso, pois frente às possibilidades de manifestações clinicas e características da reabilitação da síndrome é importante assegurar que cada pessoa acometida pela STC possa vivenciar os impactos funcionais, psicológicos e sociais de maneira única a partir de sua subjetividade e história de vida e culminar em experiências diferentes das aqui relatadas.

Entretanto, é válido indicar que os apontamentos aqui destacados sinalizam importantes questões para as quais as equipes de reabilitação devem se atentar, como a importância da família no enfrentamento do diagnóstico ao longo do desenvolvimento do sujeito, a presença de situações de violência no ambiente escolar e a possibilidade de posturas menos ativas da vítima e a importância do suporte psicológico no processo de tratamento, principalmente nos momentos cirúrgicos, indo ao encontro do que a literatura indica como papel do psicólogo em equipe de saúde. Sugere-se novas pesquisas com olhar qualitativo que possam ampliar o conhecimento sobre a experiência de ser pessoa com STC e o processo de reabilitação nos diversos aspectos: conhecer o diagnóstico desde o nascimento e iniciar a reabilitação na idade ideal produzem experiências de menor sofrimento emocional? Qual o papel da comunicação na família no enfrentamento de situações de bullying? Questionamentos pertinentes que surgem após esse estudo e que merecem investigação.

\section{Contribuições dos autores}

Guedes, E. G. participou da concepção, delineamento, busca e análise dos dados da pesquisa, interpretação dos resultados, redação e encaminhamento do artigo cientifico. Ribas, M. C. e Abramides, D. V. M. participou da concepção, delineamento, interpretação dos resultados e redação do artigo cientifico.

\section{Conflitos de interesses}

Nenhum conflito financeiro, legal ou político envolvendo terceiros (governo, empresas e fundações privadas, etc.) foi declarado para nenhum aspecto do trabalho submetido (incluindo, mas não se limitando a subvenções e financiamentos, participação em conselho consultivo, desenho de estudo, preparação de manuscrito, análise estatística, etc.).

\section{Referências}

Abreu, D. B., \& Zacharias, D. G. (2016). Psicoterapia e adolescência. Boletim Entre SIS, 1(1). Recuperado de https://online.unisc.br/acadnet/anais/index.php/ boletimsis/article/view/16148

Alfonso, L. S., \& Centelles, I. A. (2016). Síndrome de Treacher Collins en una familia cubana. Presentación de caso. Revista Habanera de Ciencias Médicas, 15(3), 408417. Recuperado de https://www.researchgate.net/ publication/317514063_Sindrome_de_Treacher_Collins_ en_una_familia_cubana_Presentacion_de_caso

Alves, E. G. R. (2016). Considerações psicossociais sobre deformidade facial: a pessoa, a família e os profissionais de saúde. Jundiaí: Paco Editorial. 
Andrade, E. C., Santos Júnior, V., Didoni, A. L. S., Freitas, P. Z., Carneiro, A. F., \& Yoshimoto, F. R. (2005). Síndrome de Treacher Collins com atresiacoanal: relato de caso e revisão de suas características. Revista Brasileira de Otorrinolaringologia, 71(1), 107-110. Recuperado de http://www.scielo.br/scielo.php?pid=S0034$72992005000100021 \&$ script=sci_abstract\&tlng=pt. doi: 10.1590/S0034-72992005000100021

Barbosa, M. A. M., Balieiro, M. M. F. G., \& Pettengill, M. A. M. (2012). Cuidado centrado na família no contexto da criança com deficiência e sua família: uma análise reflexiva. Texto \& Contexto Enfermagem, 21(1), 1949. Recuperado de http://www.scielo.br/scielo. php?pid=S0104-07072012000100022\&script=sci_ abstract\&tIng=pt. doi: $10.1590 /$ S0104-07072012000100022

Bardin, L. (2009). Análise de conteúdo. Lisboa: Edições 70.

Borges, L. M., \& Soares, M. R. Z. (2018). Formação do psicólogo da saúde. In E. M. F. Seidl, M. C. O. S. Miyazaki, A. T. A. RamosCerquira, \& N. A. M. Domingos (Orgs), Psicologia da Saúde: teorias, conceitos e práticas (pp. 21-52). Curitiba: Juruá.

Câmara, R. H. (2013). Análise de conteúdo: da teoria à prática em pesquisas sociais aplicadas às organizações. Gerais: Revista Interinstitucional de Psicologia, 6(2), 179-191. Recuperado de http://pepsic.bvsalud.org/scielo.php?script=sci_ abstract\&pid=S1983-82202013000200003\&lng=pt\&nrm=iso.

Caregnato, R. C. A., \& Mutti, R. R. (2006). Pesquisa qualitativa: análise de discurso versus análise de conteúdo. Texto \& Contexto Enfermagem, 15(4), 679-684. Recuperado de http://www.scielo.br/scielo.php?pid=s010407072006000400017\&script=sci_abstract\&tIng=pt. doi: 10.1590/S0104-07072006000400017

Carvalho, S. C., Martins, E. J., \& Barbosa, M. R. (2012). Variáveis psicossociais associadas à cirurgia ortognática: uma revisão sistemática da literatura. Psicologia: Reflexão e Crítica, 25(3), 477-490. Recuperado de http://www.scielo. br/scielo.php?pid=S0102-79722012000300007\&script=sci_ abstract\&tIng=pt. doi: 10.1590/S0102-79722012000300007

Gómez-Ortiz, O., Del Rey, R., Bolamos, J. A. C., \& Ruiz, R. O. (2014). Estilos parentales e implicación em bullying. Cultura y Educación, 26(1), 132-158. Recuperado de https://www.researchgate.net/publication/262414405_ Parenting_styles_and_bullying_involvement_ Estilos_parentales_e_implicacion_en_bullying doi: 10.1080/11356405.2014.908665

Hannum, J. S. S., Miranda, F. J., Brito, L. N. O., Costa Neto, S. B., \& Cruz, A. D. (2015). Aconselhamento Genético: Análise e Contribuições a partir do Modelo de Aconselhamento Psicológico. Psicologia: Ciência e Profissão, 35(3), 797808. Recuperado de http://www.scielo.br/scielo. php?pid=S1414-98932015000300797\&script $=$ sci_ abstract\&tlng=pt doi: $10.1590 / 1982-3703001372013$
Lodovichi, F. F., Oliveira, J. P., Denadai, R., Raposo-Amaral, C. A., Ghizoni, E., \& Raposo-Amaral, C. E. (2018). Traz a deformidade de orelha impacto negativo na qualidade de vida em indivíduos com síndrome de Treacher Collins? Ciência \& Saúde Coletiva, 23(12), 43114318. Recuperado de http://www.scielo.br/scielo. php?script=sci_arttext\&pid=S1413-81232018001204311. doi: $10.1590 / 1413-812320182312.21142016$

Martini, A. (2011). Reabilitação, ética e técnica. Ciência \& saúde coletiva, 16(4), 2263-2269. Recuperado de http://www.scielo.br/scielo.php?script=sci_ arttext\&pid=S1413-81232011000400025. doi: $10.1590 /$ S1413-81232011000400025

Moreira, D. (2012). Transtorno do assédio moral bullying: a violência silenciosa (2a ed.). Rio de Janeiro: Wak Editora.

Mutarelli, A. (2015). O serviço de psicologia no hospital: modelo assistencial de cuidado na busca pela promoção de saúde. Revista da SBPH, 18(1). Recuperado de http://pepsic.bvsalud.org/scielo.php?script=sci_ arttext\&pid=S1516-08582015000100009

Oliveira-Cardoso, E. A., Garcia, J. T., Santos, L. L., \& Santos, M. A. (2018). Comunicando más notícias em um hospital geral: a perspectiva do paciente. Revista da SPAGESP, 19(1), 90-102. Recuperado de http://pepsic.bvsalud. org/scielo.php?script=sci_abstract\&pid=S167729702018000100008\&lng=pt\&nrm=iso\&tlng=pt

Passos-Bueno, M. R., \& Splendore, A. (2001). Síndrome de Treacher Collins: aspectos clínicos, genéticos e moleculares. Revista de Medicina, 80(1), 52-56. Recuperado de http://www.revistas.usp.br/revistadc/article/ view/86817. doi: 10.11606/issn.1679-9836.v80i1p52-56

Pollo Medina, J. M., Álvarez E. M. C., Torres, A. A. Y., Placeres, H. J. F., \& Morales C. D. (2014). Síndrome de Treacher-Collins. Presentación de un caso. Revista Médica Electrónica, 36(2), 211-216. Recuperado de https://pesquisa.bvsalud.org/ portal/resource/pt/lil-711082

Regen, M. (2006). A instituição família e sua relação com a deficiência. Revista do Centro de Educação, 27, 119-132. Recuperado de https://periodicos. ufsm.br/educacaoespecial/article/view/4357. doi: 10.5902/1984686X

Saldanha, S. V., Rosa, A. B., \& Cruz, L. R. (2013). O psicólogo clínico e a equipe multidisciplinar no Hospital Santa Cruz. Rev. SBPH, 16(1), 185-198. Recuperado de http://pepsic.bvsalud.org/scielo.php?script=sci_ arttext\&pid=S1516-08582013000100011 
Seidl, E. M. F., Ramos-Cerqueira, A. T. A., Nogueira, G. S., Graner,

K. M., Borges, L. M., Malagris, L. E. N., ... Rudnicki, T. (2018).

Psicologia da saúde: conceitos e modelos explicativos. In

E. M. F. Seidl, M. C. O. S. Miyazaki, A. T. A. Ramos-Cerquira,

\& N. A. M. Domingos (Orgs), Psicologia da saúde: teorias, conceitos e práticas. Curitiba: Juruá.

Terrazas, K., Dixon, J., Trainor P. A., \& Dixon, M. J. (2017).

Raresyndromes of the headand face: mandibulofacial and acrofacialdysostoses. Wiley Interdiscip Rev Dev Biol, 6(3). Recuperado de https://www.ncbi.nlm.nih.gov/ pubmed/28186364. doi: 10.1002/wdev.263

Vieira, A. G., \& Waischunng, C. D. (2018). A atuação do psicólogo hospitalar em Unidades de Terapia Intensiva: a atenção prestada ao paciente, familiares e equipe, uma revisão da literatura. Rev. SBPH, 21(1), 132-153. Recuperado de http://pepsic.bvsalud.org/scielo.php?script=sci_ abstract\&pid=S1516-08582018000100008\&lng=pt\&nrm=iso 